\title{
Sense of Community in Gated and Non-Gated Residential
}

\author{
Siti Rasidah Md Sakip ${ }^{1}$, Noraini Johari¹, Mohd Najib Mohd Salleh² \\ ${ }^{1}$ Faculty of Architecture, Planning \& Surveying, Universiti Teknologi MARA, Perak \\ 2 Universiti Sains Malaysia, Pulau Pinang, MALAYSIA \\ sitir704@perak.uitm.edu.my
}

\begin{abstract}
Neighbourhood design is one of the factors contributing towards the establishment and maintenance of local community ties. The differences in environmental size and design of neighbourhoods are perceived to influence sense of community networking functions. A physical element such as gated element is also believed to have an influence on local community relationship networking. Therefore, a study on sense of community was conducted in two neighbourhood areas: Putrajaya (non-gated) and Bandar Baru Bangi (gated) using face to face interview method. This study found that residents of nongated residential areas demonstrated higher sense of community $(M=6.47 S P=0.08)$ than residents of gated residential areas $(M=6.39, S P=1.08)$.

Keywords: sense of community; social interaction; neighbourhood design; gated residential; non-gated residential

eISSN 2514-751X @ C 2018. The Authors. Published for AMER ABRA cE-Bs by e-International Publishing House, Ltd., UK. This is an open-access article under the CC BY-NC-ND license (http://creativecommons.org/licenses/bync-nd/4.0/). Peer-review under responsibility of AMER (Association of Malaysian Environment-Behaviour Researchers), ABRA (Association of Behavioural Researchers on Asians) and $c E-B s$ (Centre for EnvironmentBehaviour Studies), Faculty of Architecture, Planning \& Surveying, Universiti Teknologi MARA, Malaysia.

DOI: https://doi.org/10.21834/aje-bs.v3i9.303
\end{abstract}




\subsection{Introduction}

Sense of community is a relationship involving social interaction within a community resulting in a sense of belonging within the group and a perception of ownership through sharing of needs and requiring each other's commitment (McMillan \& George, 1986). In the context of a neighbourhood, community relationships provide the satisfaction of living in a residential area (Blanchard, 2008; Fried, 1984), and are also significant determinants of the general quality of life and satisfaction in well-being (Rogers \& Sukolratanametee, 2009). It implies a physical area in different sizes and forms to make resident feels socially connected (Talen, 1999). A physical element such as gated element also influences the sense of community in neighbourhoods (Rogers \& Sukolratanametee, 2009). Previous research demonstrates that sense of community in gated communities is higher as compared to that in non-gated ones (Blandy \& Lister, 2003; Serife, 2007). This relationship believed to be influenced by a few factors such as income level, and similar interests among residents (Blandy \& Lister, 2003). However, Georjeanna (2000) found that the residents with higher-income levels have lower sense of community compared to residents with medium or low income levels.

Gated community defined as a physical space that separated from its surrounding by fenced or walled elements and separated from another neighbourhood (Blakey \& Snyder, 1997). However, in Malaysia's context, typical residential developments comprise elements of gating at every lot. While, the concept of non-gated individual residential units is still seldom applied (Siti Rasidah, Aldrin, \& Mohd Najib, 2011). Therefore, this study focused on gated and non-gated residential areas as proposed by Siti Rasidah et al. (2011) because gated community in Malaysia targeted for higher-income earners, (JPBD, 2009) and the gated element is different from that proposed by Blakely and Synder (1997). In Malaysia, the gated element in gated community entails two gates namely at every lot and the perimeter of the residential area. That means there have a couple of gated elements with a security guard post at the entrance to the residential area (Siti Rasidah et al., 2011). Therefore, the objective of this paper is to examine the relationships between sense of community and neighbourhood designs with gated and non-gated elements.

\subsection{Literature Review}

Sense of community is one of the indicators of the quality of life in social classes (Blanchard, 2008; Fried, 1984). It can be described as the simplest first grouping beyond the family which has social significance and which is conscious of some local unity (Ashok Kumar, 1973). In other words, a sense of community associated with the commitment given by the members of the community to others in society. Sense of community is an important aspect in a neighbourhood to enhance feelings of safety and eliminate the opportunities for crime (Austin, Furr, \& Spine, 2002). However, in terms of neighbourhood designs, it will influence the relationship between communities, especially in physical environments. Talen (1999) argued that an environmental factor is one of the factors that influence and stimulate community relations. The frequency of these relationships is the quality in the sense of community. Uzzell, Pol and Badenas (2002) found that physical and social environment elements can enhance relationships among residents using community space in two 
Guildford neighbourhoods, Surrey, England.

Rogers and Sukolratanametee (2009) argued that an attractive physical environment will increase the sense of community as spaces created and provided in neighbourhood areas maintain continuity towards spatial integration. Previous research at four suburban, metropolitan neighbourhoods in Houston found that residential areas with ecological designs have a higher sense of community (Rogers \& Sukolratanametee, 2009). Ecological design such as mini-parks and pedestrian walkways believed to encourage outdoor activities in the space provided. Those activities, leading higher social interaction and networking compare to other neighborhood without or less outdoor activities (Rogers \& Sukolratanametee, 2009).

In the physical environment, five elements believed to enhance the community relationship, namely architecture and site design, density and scale, streets, public space, and mixed land uses (Talen, 1999). Architecture and site design defined as social interactions promoted by designing residences. The residents encouraged to get out of their houses and out into the public sphere. Density and scale refer as the sense of community and neighbourliness engendered by having small-scale, well-defined neighbourhoods with clear boundaries and a clear centre. Meanwhile, streets designed to encourage street life, since any increase in pedestrian activity will strengthen community bonds and promote a sense of place. Public space also provides a venue for chance encounters, which serves to strengthen community bonds. The gathering places in neighbourhoods give heart' to the community and serve as a communication place. Finally, mixed land uses as mentioned by Jane Jacobs (1961) as the mixture of residential and commercial land uses, create a multipurpose space in which lingering encouraged, creating a setting for "repetitive chance encounters" to build and strengthen community bonds.

Therefore, gated feature is one of the physical elements in architecture which believed to have an influence on community relationships in neighbourhoods. According to Atkinson and Blandy (2005), gated elements in gated communities, cause a loss of social diversity in the neighbourhoods that lead a tendency towards social segregation. This form of segregation based on the concept of social class. Roitman (2003) argued that this concept referred to as similar characteristics regarding their productive activities and consequently, have similar economic resources due to similar developed skills and also share similar habits regarding patterns of consumption. It known as a concept of social class. Therefore, Blandy and Lister (2003) as well as Serife (2007) found that sense of community in gated community is higher than to non-gated community. However, the sense of community in Atkinson and Blandy (2005), Roitman (2003) and Serife (2007) studies referred to the concept of gated community as proposed by Blakely and Synder (1997). However, in the Malaysian context, the typical neighbourhood design refers to a definition as proposed by Siti Rasidah et al. (2011). Gated community in Malaysia known as gated and guarded community and targeted for higherincome earners (JPBD, 2009). It must be noted that the objective of this study is to examine the sense of community in gated and non-gated residential areas, in the Malaysian context.

\subsection{Measure of Dimensions}

Sense of community (SOC) measured as the identification of the community members' feelings about each other and the community's successful functioning because it leads to the 
satisfaction with and commitment to the community. This SOC constructs measured by four dimensions adapted from McMillan and George (1986). The four dimensions of SOC are (a) membership: involving boundaries, emotional safety, a right' to belong, personal investment and a common symbol system; (b) influence: which has to do with group conformity; (c) integration and fulfillment of needs: concerned with the importance of community relations that perceived to be the motivation to create and maintain a continuous feeling of esprit de corps and (d) shared emotional connections is refer to interaction, shared events, and tied into the psychological aspects of sense of community as opposed to other affective notions.

Table 1. Sense of community indicators

\begin{tabular}{|c|c|c|}
\hline Indicators & Description of instrument & \\
\hline Membership & $\begin{array}{l}\text { I can identify most of the residents here. } \\
\text { Most of the community knows me. } \\
\text { I always participate in community activities organised } \\
\text { by the community association. }\end{array}$ & $\begin{array}{l}1=\text { Strongly disagree } \\
10=\text { Strongly agree }\end{array}$ \\
\hline Influence & $\begin{array}{l}\text { I look after my neighbours' children/plants/pets when } \\
\text { they go on vacations. } \\
\text { I value my neighbour's/community's views or } \\
\text { comments. } \\
\text { Whenever there are problems in this residential area, } \\
\text { they are solved by the community. }\end{array}$ & $\begin{array}{l}1=\text { Strongly disagree } \\
10=\text { Strongly agree }\end{array}$ \\
\hline $\begin{array}{l}\text { Integration and } \\
\text { fulfillment of } \\
\text { needs }\end{array}$ & $\begin{array}{l}\text { I feel that I am one of the community members in this } \\
\text { residential area. } \\
\text { I can trust the community here. } \\
\text { I feel this residential area is good to live in. }\end{array}$ & $\begin{array}{l}1=\text { Strongly disagree } \\
10=\text { Strongly agree }\end{array}$ \\
\hline $\begin{array}{l}\text { Shared emotional } \\
\text { connection }\end{array}$ & $\begin{array}{l}\text { I am happy living among the community in this } \\
\text { residential area. } \\
\text { The community here always share important events } \\
\text { such as birthday parties, weddings, festivals } \\
\text { (Deepavali, Hari Raya and so on). } \\
\text { The community here care about each other. }\end{array}$ & $\begin{array}{l}1=\text { Strongly disagree } \\
10=\text { Strongly agree }\end{array}$ \\
\hline
\end{tabular}

The SOC dimension measured by three indicators using a questionnaire. The measurement of SOC rated using a Likert scale ranging from 1 to 10 whereby scale 1 is "Highly Disagree" and scale 10 "Highly Agree" as shown in Table 1. The high score will indicate that the community relationship in the neighbourhood is high and vice versa if the score obtain is low. The validation of the sense of community constructs done by conducting confirmatory factor analysis (CFA) using AMOS and SPSS software. CFA is a measurement model used to specify the relationship between factors and their respective indicators and the relationship between indicator errors. The CFA method is able to ensure and validate the items used in measuring latent variables by taking into account the value of the variances. In 
CFA, several indices employed to judge whether the model tested fits to the data. The indices are Chi-square, Chi-square/degree of freedom ratio, and goodness of fit indices. Results from the measurement model of SOC construct to demonstrate that only one item in fulfillment of needs indicator omitted (Item 2=, I can trust the community here) due to low levels of factor loadings $(\lambda<0.3)$ in the initial measurement model analysis. The reliability test for SOC construct indicated acceptable internal consistency ( $\alpha=0.64$ to 0.90 ) with corrected item-total correlation for all variables higher than 3.0, (the accepted cut-off-value according to de Vaus, 2002) and the factor loading is higher than $0.3(\lambda=0.62$ to 0.94$)$. The goodness-of-fit indices indicating just identified' (GFI=1.00 CFI=1.00, RMSEA $=0.56$ to 0.76 ) shows that this model accepted as the indicator for the SOC construct.

\subsection{Methodology}

This study using face to face structured, and formal interviews used to obtain the data. The settings of the interviews were the preselected residential areas in Presint 9 in Putrajaya and Seksyen 4 Bandar Baru Bangi. The focus of this study involved groups of residents in a medium high level of income between RM3000 to RM5000 and categorized as able to afford the medium-high cost houses (JPBD, 2009; Putrajaya, 2009). The study employs the population survey approach on two individual gated residential areas in Bandar Baru Bangi and individual non-gated residential areas in Putrajaya. Total population involved in this study is 457 after eliminated 19 respondents in the selection list as they identified as having non residential uses. However, only 171 respondents contribute in this study.

Individual non-gated residences selected first followed by the selection of individual gated residences. In Malaysia, individual non-gated residences (INGR) very limited. Therefore, Putrajaya chosen as the study area because it is the first residential area in Malaysia to practice the non-gated concept (Roslan Talib, 2009). The selection adapted from WilsonDoenges's (2000) as well as the Perkins, Wandersman, Rich dan Taylor (1993). The gated community selected first before selecting non gated community using five criteria, which are: (a) the size of the residential area which is based on a residential land lot size of at least 150 square metres; (b) a stable community where the residential area has to have been occupied for a period of 5 years; (c) ethnic or racial composition where 90 percent of the residents inhabiting the housing area have to be made of Bumiputera or from the Malay race; (d) house design of double storey terrace units; and (e) level of income; which could not be taken into consideration as the information was confidential. Based on these selected criteria, two residential areas were found to fulfil the criteria. 9B Street and 9D Street in Precinct 9B, Putrajaya selected as INGR and 4/7 Street, Section 4, Bandar Baru Bangi selected as individual gated residences (IGR).

\subsection{Results and Discussion}

From 171 respondents participated in this study, 90 respondents are from IGR and 81 INGR. The result demonstrated that the female respondents $(65.4 \%)$ is higher compared than to male respondents (34.6\%) in INGR. Meanwhile in IGR, the number of male respondents is 
higher (70\%) compared than to female respondents (30\%). In terms of ethnicity, the dominant respondents in both areas are Malay Muslims (INGR: 100\%, IGR: 93.3\%). Using the t-test, this study found that marital status has significant influence on sense of community in IGR (t $(88)=-2.22 ; p=0.02$ ), but no significant difference on sense of community in INGR (t $(6.43)=$ $0.75 ; p=0.47)$. This result shows that married respondents at IGR $(M=6.46)$ have a higher sense of community compared to single respondents $(M=5.53)$ as shown in Figure 1.

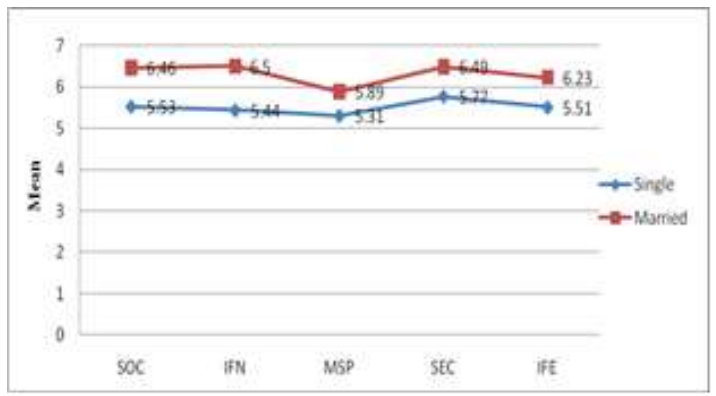

Fig.1. Comparison between sense of community and their dimensions with marital status in individual gated residential areas (IGR)

Note: $\mathrm{SOC}=$ sense of community, IFN= integration \& fulfilment of needs, MSP= membership, $S E C=$ shared emotional connection, IFE= influence

As shown in Figure 1, the comparison between SOC dimensions shows all SOC dimensions, namely integration and fulfillment of needs (Married: $M=6.5$, Single: $M=5.44$ ); membership (Married: $M=5.89$ Single: $M=5.31$ ); shared emotional connections (Married: $M=6.49$, Single: $M=5.77$ ) and; influence (Married: $M=6.23$, Single: $M=5.51$ ); are higher in married respondents than unmarried respondents. Meanwhile, results from the One-way ANOVA test found that the length of occupancy in the residential area was significant in INGR $(F(4,76)=5.83, p<0.05)$ whilst for IGR was $(F(4,85)=2.56, p<0.05)$. This finding shows that the longer a respondent resides in a residential area (INGR and IGR), the higher sense of community nurtured. This result shows in Figure 2:

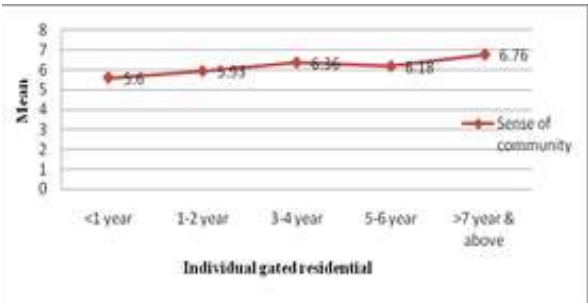

(a)

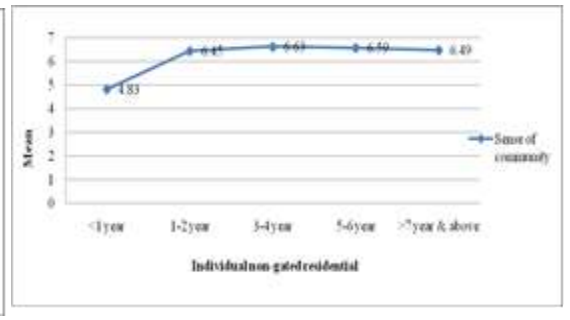

(b)

Figure 2: (a) Sense of community with the length of occupancy in IGR; (b) Sense of community with the length of occupancy in INGR 
However, in comparing age and sense of community against types of residential areas, there are significant differences between age and SOC in INGR $(F(3,77)=2.73, p<0.05)$, but no significant differences in $\operatorname{IGR}(F(4,85)=0.64, p>0.05)$. This finding indicates that when the age of the respondents increased, the community relations are decline. This finding evidenced from Figure 3.

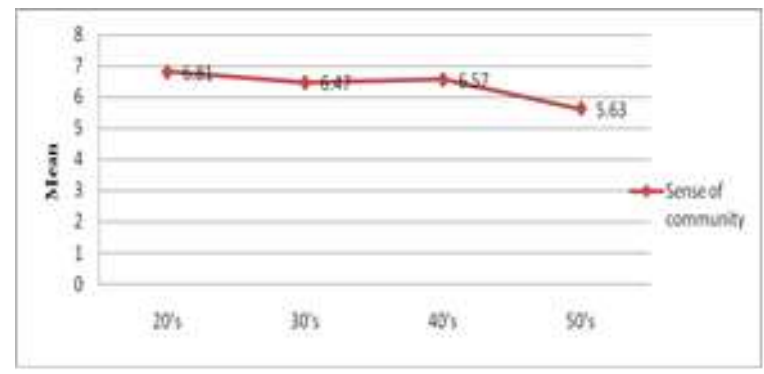

Figure 3: Sense of community with the level of age in individual non-gated residential areas

By referring to Figure 3, the sense of community of the respondents in INGR deteriorates with age. This based on a mean score of SOC for age levels 20's ( $M=6.81) 30$ 's $(M=6.47)$, 40 's $(M=6.57)$ and 50's $(M=5.63)$.

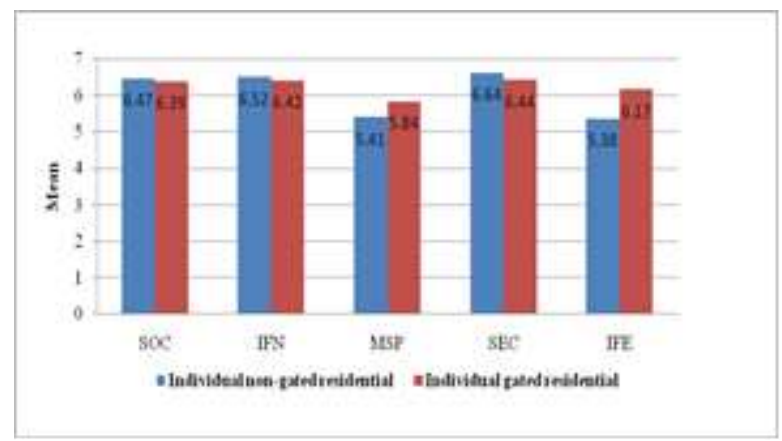

Fig.4. Comparison of sense of community and their dimensions in individual gated and non-gated residential areas

Note: SOC= sense of community, IFN= integration \& fulfilment of need, MSP= membership, SEC= shared emotional connection, IFE= influence

As mentioned earlier, the objective of this paper is to examine the sense of community in two types of residential based on the gated element. Thus, the findings of the study demonstrated that the sense of community in individual non-gated residential areas (INGR) is higher $(\mathrm{M}=6.47 \mathrm{SP}=0.88)$ as compared to sense of community in individual gated residential areas (IGR) $(\mathrm{M}=6.39, \mathrm{SP}=1.08)$. In comparing between $\mathrm{SOC}$ dimensions against types of residential area, the results show the dimensions of integration and fulfillment of needs (INGR: $M=6.52, S P=0.89$, IGR: $M=6.42, S P=1.25$ ) and shared emotional connections 
(INGR: $M=6.64, S P=1.05$, IGR: $M=6.44, S P=1.06$ ) were higher at INGR as compared to IGR. On the other hand, membership (IGR: $M=5.84, S P=1.23$, INGR: $M=5.41, S P=1.17$ ) and influence dimensions (IGR: $M=6.17, S P=1.19$, INGR: $M=5.38, S P=1.18$ ) were higher in IGR than compared to INGR. Based on these comparisons among the SOC dimensions, it can be said that the dimension of shared emotional connections was the main dimension in nurturing local community ties at both types of residential areas. This finding is clearly shows by Figure 4:

\subsection{Conclusion}

The objective of this paper is to investigate the sense of community at two types of residential areas namely individual gated residential areas (IGR) and individual non-gated residential areas (INGR). This study found that SOC is higher at INGR as compared to that in IGR. The findings of this study support Wilson-Doenges' (2000) study, which also found that residents in non-gated residential areas (gated elements refer to the gated community) have a higher sense of community as compared to those in gated communities. Talen (1999) argued that this may be caused by environmental factors and the physical layout of residential areas that influence the community ties. Social interaction among residents will be enhancing in an environmental design and building physical designs that motivate them to go out for recreation (Talen, 1999). In addition, this study also found that married residents have a higher sense of community. This clarified by Campbell and Lee (1992) by proposing that the number of children in a family is one of the factors in community relations. Community relations formed when the relationship among children in the community as childhood friends will lead to the formation of ties among parents. The findings of this study concur with past research (McCulloch, 2003; McMillan \& George, 1986) that the occupational period of the residential area is one of the indicators of tight community relations. This study has proven that residents at both types of residential areas (IGR and INGR) have a higher sense of community the longer they reside in that area. This believed to involve strengthening of sense of belonging and sharing within a neighbourhood, giving rise to good community relations.

In this study, ethnic demography forms one of the limitations. The majority of respondents are Malay Muslim ethnic group. Hence, this study focused on racially homogeneous. Thus, the findings of the study skewed towards the community relations for a homogeneous ethnic demography. Therefore, this study proposed for future research should take into account the diversity of ethnicity to obtain more generalized findings.

\section{References}

Fachinger, J., den Exter, M., Grambow, B., Holgerson, S., Landesmann, C., Titov, M., et al. (2004). Behavior of spent HTR fuel elements in aquatic phases of repository host rock formations, 2nd International Topical Meeting on High Temperature Reactor Technology. Beijing, China, paper \#B08.

Hafazah, A., K., \& Siti Mareenah, A., R. (2010). Community Participation: Towards a Safer Housing Environment. Asian Journal of Environment-Behaviour Studies, 1(2), 19-31. 
Heng Z., \& Siu, L., L. (2013). Assessing the renovation of existing residential buildings regarding environmental efficiency. Asian Journal of Environment-Behaviour Studies, 4(14), 19-35

Mehdi K., \& Koorosh, A. (2015). Achievement to Environmental Components of Educational Spaces for Iranian Trainable Children with Intellectual Disability. Procedia - Social and Behavioral Sciences, 201, 9-18.

Mettam, G. R., \& Adams, L. B. (1999). How to prepare an electronic version of your article. In B. S. Jones \& R. Z. Smith (Eds.), Introduction to the electronic age (pp. 281-304). New York: E-Publishing Inc.

Strunk, W., Jr., \& White, E. B. (1979). The elements of style (3rd ed.). New York: MacMillan.

Wichitra, S., Kidanun D., \& Warapon, K. (2012). Household Recycling Behaviours and Attitudes toward Waste Bank Project: Mahasarakham Municipality. Journal of ASIAN Behavioural Studies, 2(6), 35-47. 